\title{
GAIA Level 2 Major Internal Structural Defect
}

National Cancer Institute

\section{Source}

National Cancer Institute. GAIA Level 2 Major Internal Structural Defect. NCI Thesaurus. Code C127962.

GAIA Level 2 Major Internal Structural Defect is defined by three criteria: first, the defects are prenatal in origin; second, the defect(s) affect (or have the propensity to affect) the health, survival, or physical or cognitive functioning of the individual; third, one of the following requirements must be met: a) For a live birth, alterations in the internal anatomy must be present at the time of live birth, must persist beyond the immediate peripartum period unless surgically repaired, and require documented confirmation of a diagnosis made by a clinician who is experienced in diagnosing congenital anomalies, and who has the highest level of morphology training for the specific setting without using definitive imaging or intraoperative evaluation; OR b) For a stillbirth, or for a spontaneous or therapeutic abortion, an internal structural defect is visible prenatally either by ultrasound or by other imaging modality. 